\title{
Erratum to: Evaluation of antioxidant potential of ethyl acetate fraction of Rosmarinus officinalis L. and its major components
}

Ho Bong Hyun ${ }^{1}$ Sabina Shrestha ${ }^{2}$ - Kyung Hwan Boo ${ }^{1,2}$. Somi Kim Cho ${ }^{1,2}$

Published online: 28 June 2016

(C) The Korean Society for Applied Biological Chemistry 2016

Erratum to: J Korean Soc Appl Biol Chem (2015) 58(5):715-722

DOI 10.1007/s13765-015-0097-8

Unfortunately, there is an error in Acknowledgment section of the published article (10.1007/s13765-015-0097-8). The funding number, 2014047495, should be corrected to 2009-0094059.

The online version of the original article can be found under doi:10.1007/s13765-015-0097-8.

Somi Kim Cho

somikim@jejunu.ac.kr; phd.kim.somi@gmail.com

1 Faculty of Biotechnology, College of Applied Life Sciences, SARI, Jeju National University, Jeju 690-756

Republic of Korea

2 Subtropical Horticulture Research Institute, Jeju National University, Jeju 690-756, Republic of Korea 